\title{
The passing of giants
}

\author{
Lloyd R Sutherland MD MSc FRCPC FACP
}

F or many C anadians, 2002 will be remembered as the year of the death of Elizabeth, the Q ueen M other. For those of us interested in the fields of gastroenterology and hepatology, however, this year will be also remembered for the deaths of Dame Sheila Sherlock and Dr Sidney Truelove. 0 ur understanding of the diseases of the liver and the therapeutics of inflammatory bowel disease was enhanced and broadened by their many contributions.

Both had links with $C$ anada. Dame Sherlock was a popular visiting professor in $\mathrm{C}$ anada. She always took the side of the practitioner, offering prudent advice and pithy summations. M y first recollection of Professor Sherlock was her appearance at the 25th annual meeting of the A merican A ssociation for the Study of the Liver in Chicago to give the Jubilee oration. Bill Summerskill, by that time well established in the North A merican community and at the $M$ ayo $C$ linic, introduced her and noted that he owed many debts of gratitude to Professor Sherlock, chief among which was the advice that there was room for only one hepatologist in the $U$ nited Kingdom.

Dame Sheila did not avoid controversy either. At the annual meeting of the Royal College of Physicians and Surgeons of $C$ anada, she correctly predicted that liver transplantation programs, then in their early days, would soon turn to performing transplantations for patients with alcohol-related liver disease, because the reserve of patients with chronic liver disease would be insufficient to support the new facilities.

$\mathrm{H}$ er contributions to the literature were many. I will only highlight her classic textbook on the liver and liver disease (1) and her influential role in establishing liver biopsy as an important diagnostic test. During a visit to Toronto in 1977, she was introduced to an audience as "someone who needs no introduction, Sheila Sherlock".

Sidney Truel ove established the central role of the clinical trial in the therapy of inflammatory bowel disease. Over three decades, his studies of the effectiveness of sulfasal azine and corticosteroids in the induction and maintenance of remission informed the world and improved the quality of life for patients with ulcerative colitis. In addition to establishing randomized, controlled clinical trials as the gold standard for decision-making, his careful record keeping provided a rich and productive stream of papers describing the natural history of ulcerative colitis and C rohn's disease. $\mathrm{H}$ is final major contributions were the elegant study with A zad Khan (2) demonstrating that 5-acetylsalicylic acid was the active moiety of sulfasalazine and the founding of the International Organization for the Study of Inflammatory Bowel Disease (IOIBD), recognized today as including many of the opinion leaders in inflammatory bowel disease. By a curious coincidence, Truel ove died in mid-A pril, at the time of the annual Truelove lecture (Judy Chow, U niversity of Chicago) during the annual meeting of the IOIBD.

A Ithough both made important contributions to the literature, I believe they both took greater pride in the registrars and fellows they trained. How many women entered hepatology because of the role model they saw in Sherlock in those early days? How many today consider hepatology because of J enny H eathcote, a Sherlock trainee? $\mathrm{H}$ ow many registrars or house officers such as $\mathrm{A}$ lan Thomson focused on inflammatory bowel disease as a career after being exposed to Truelove's enthusiasm and interest in the disease?

I cannot say that I knew either well. I recall attending a dinner where Dame Sheila, M M (W oody) Fisher and Jenny Heathcote discussed the merits of French fries. I met Truelove several times during my sabbatical at Oxford in the mid-1990s. He appeared to be enjoying his retirement, spending time in his allotment working on his garden sporting a battered white Stetson, reputedly given to him on his visit to C al gary.

Rest in peace.

\section{REFERENCES}

1. Sherlock S, Dooley J. Diseases of the Liver and Biliary System, 11th edn. Oxford: Blackwell Science Ltd, 2001.

2. A zad Khan A K, Piris J, Truelove SC. A n experiment to determine the active therapeutic moiety of sulphasalazine. Lancet 1977;ii:892-5. 


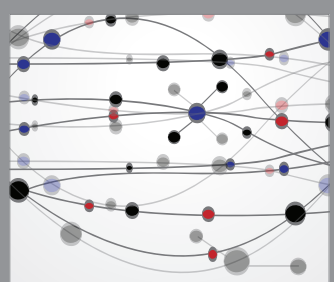

The Scientific World Journal
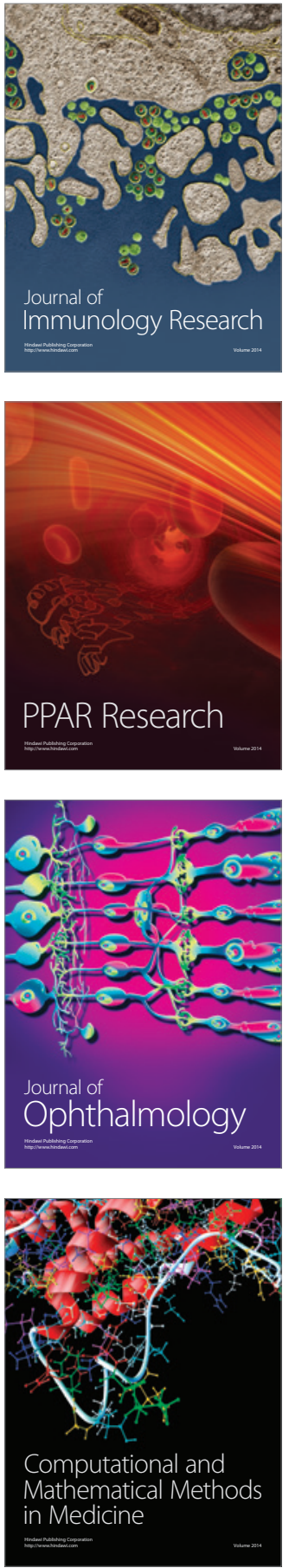

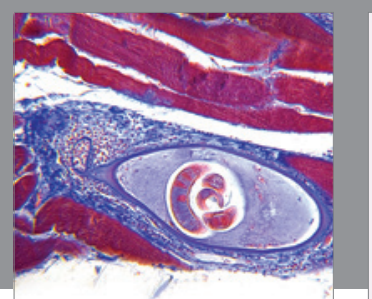

Gastroenterology Research and Practice

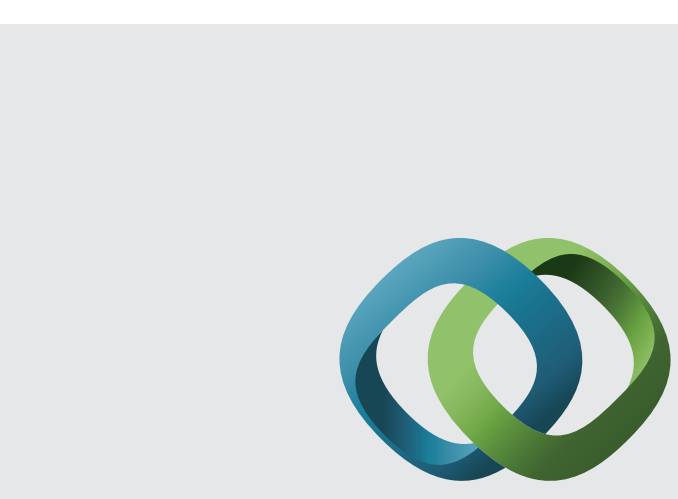

\section{Hindawi}

Submit your manuscripts at

http://www.hindawi.com
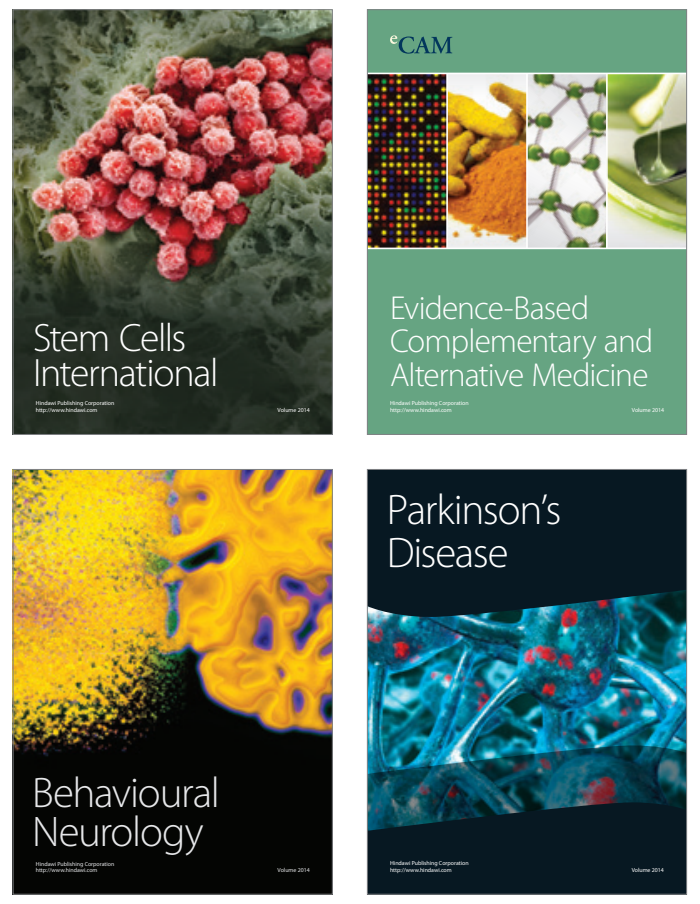
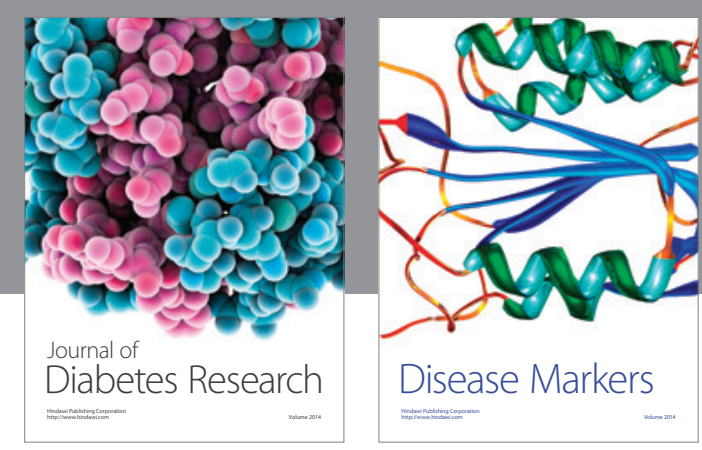

Disease Markers
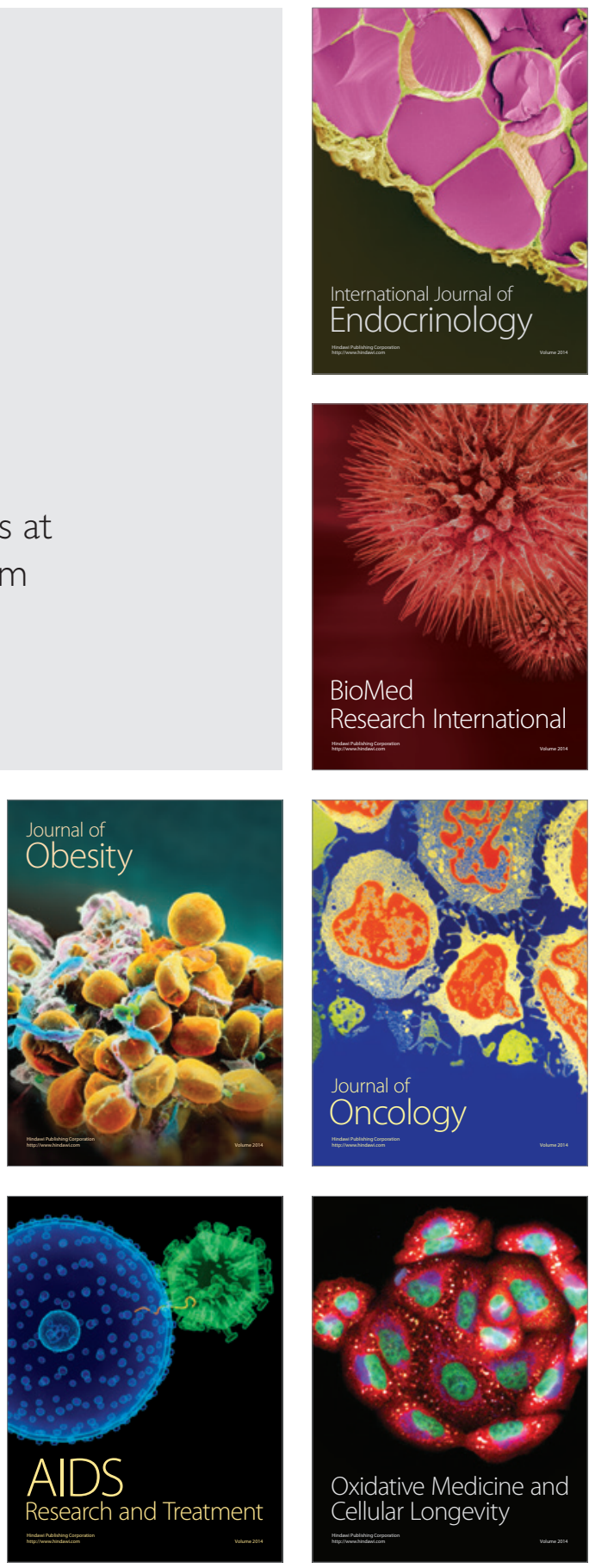